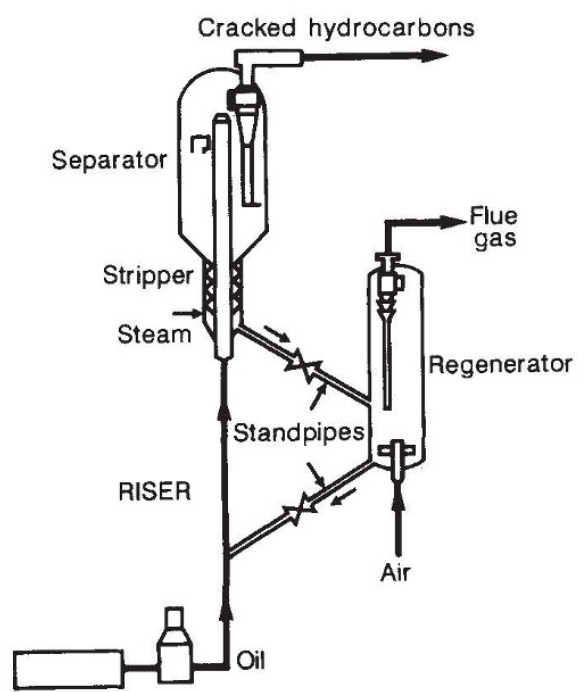

Catalytic cracking plant Elf style.

through an air-driven regenerator whose chief function is to remove solid carbon, or 'coke', from the catalyst (see figure).

In the drive for increased gasoline output, schemes for the hydrogenation of heavier crude fractions are being canvassed, further complicating the optimization of cracking plants.

At Solaize, the joint Elf-CNRS team has been forced back to basics, fitting a pilot-plant housed in a hangar-like building with instruments and using radioactive tracers for tracking the movement of zeolite through its cycle. The objective is to refine a mathematical model of a cracking plant which is being elaborated, with the objective of fixing the parameters of more efficient cracking plants linked with hydrogenation units. The same model will eventually be the basis of programs for the automated control of refinery operations.

Bernard enthuses about the niceties of the operation of standard cracking plants which the study has brought to light. Even questions such as the effect of the riser walls on the movement of zeolite had previously gone unanswered, he says. That there should be friction had been expected, but the velocity profiles across the riser that have now been measured, and the patchiness of zeolite concentration across the riser, were not expected.

Nobody at Solaize is able to say what the economic benefits of the programme will be. Rather, the assumption seems to be that a business which depends on the successful operation of machines such as cat crackers had better understand them in as much detail as it can.

Elf is not alone among French companies in having taken a deliberate decision in the past decade to spend more of its effort on basic research. Claude Jablon, corporate director of research, says that the company (which differs from more conventional oil companies in its strong interest in chemicals and pharmaceuticals) employs 4,500 people in research laboratories scattered through France, elsewhere in Western Europe and in North America. Of this effort, engaging some 4 per cent of the company's total staff, he reckons that 10 per cent is devoted to projects that will yield benefits only in the long term.

Just where the project to develop better asphalt fits in this is not clear. The company appears to have something of a success with a material called 'Styrelf', selling 300,000 tonnes a year of it. The idea is that hydrocarbon molecules of regular asphalt (non-volatile refinery fractions) have been covalently linked with styrene to form a kind of threedimensional molecular network in which road metal (graded granite fragments) for highway surfaces can be embedded. Energy is being spent on the materials testing of various compositions of road surfaces, but, in the absence of a full understanding of why highway surfaces wear out or become distorted, faith is required to assure highway authorities that polymeric asphalt will last longer.

\title{
SPACE \\ Is there profit as well as pride?
}

Over the past 25 years, France has emerged as the European leader in space technology, continuing to push forward and take expensive risks while its neighbours got cold feet. This fits with the high profile given to technology.

The academic elite graduating from the grandes écoles are called 'engineers', and electronic gadgetry sprouts regularly in Paris, from video in the metro stations to cable television. The Minitel telephonelinked interactive videotext system is the most successful in the world and France's high-speed trains (TGV) and modern metro systems are often cited as models elsewhere. High technology is seen as the key to economic survival in the next century.

France has had its own space programme since 1962, when the Centre National d'Etudes Spatiales, the national space agency, was founded. In 1975 it abandoned its own domestic rocket programme to cofound the 13-member European Space Agency (ESA).

Now, France contributes almost a third of ESA's \$1,700 million budget, ahead of Germany and Italy and four times as much as Britain. It is no accident that ESA headquarters are in Paris, that the European commercial launch consortium - Arianespace with 50 per cent of the world market - is based in France, or that the first
European cosmonaut was a Frenchman.

Always an enthusiastic partner in ESA, France pulled out all the stops at the 1987 ministerial meeting in The Hague, at which the agency's long-term plan was approved. The Hermes space plane developed by CNES was chosen to service the Columbus platform, intended as Europe's contribution to the US Freedom space station, despite criticism from Britain that the technology was out of date and that

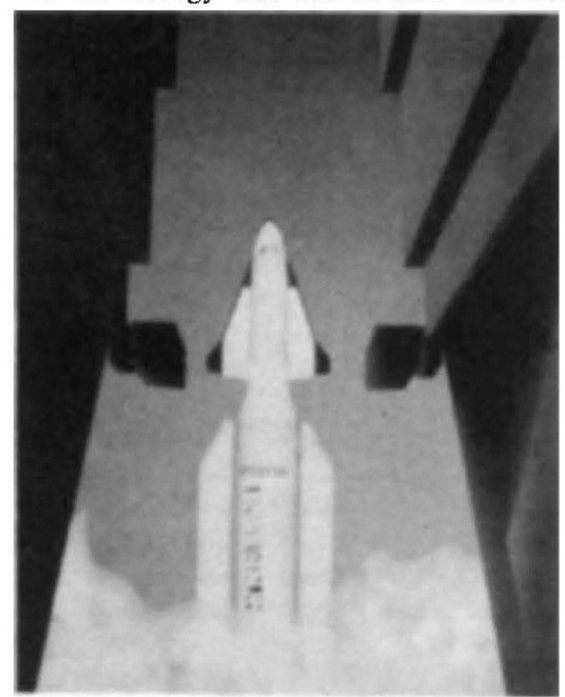

Ariane 5 will launch Hermes - both products of French initiatives. the plane was too small.

But the price of the acceptance of Hermes is that France has to foot 45 per cent of the bill, a cool FF597 million in 1990. Furthermore, Hermes depends on a new generation of heavy-lift launcher, Ariane 5, to get into space and this, too, is 45 per cent French, with costs to France running at FF1,812 million this year.

But while Britain decided that the Hermes and Ariane 5 package was simply too expensive and dropped out, France found it had money to spare to boost its domestic space programme. In the 1990 civil research budget, CNES received FF7,187 million - almost 16 per cent of the entire budget and 11 per cent more than 1989.

Of this, FF352 million will go towards a fourth generation of the SPOT commercial remote-sensing satellite owned by CNES, which will have cost an estimated FF2,500 million by the time it is launched in 1995. Although SPOT loses money, its freely available high-resolution photographs have proved a thorn in the side of superpower defence departments and a way to vaunt France's prowess.

As European space technology has a distinctive French tinge, it is fitting that the new director of ESA should be a Frenchman, Jean-Marie Luton, who came from CNES. And with some tough negotiating ahead as the full costs of Hermes and Ariane 5 emerge, Luton will need all the backing he can get.
Peter Coles 